PREPARED FOR THE U.S. DEPARTMENT OF ENERGY, UNDER CONTRACT DE-AC02-76-CHO-3073

PPPL-2943

- UC-420,421,427

MODELING OF MeV ALPHA PARTICLE ENERGY TRANSFER TO LOWER HYBRID WAVES

BY

J. SCHIVELL, D.A. MONTICELLO, N. FISCH AND J.M. RAX

OCTOBER, 1993
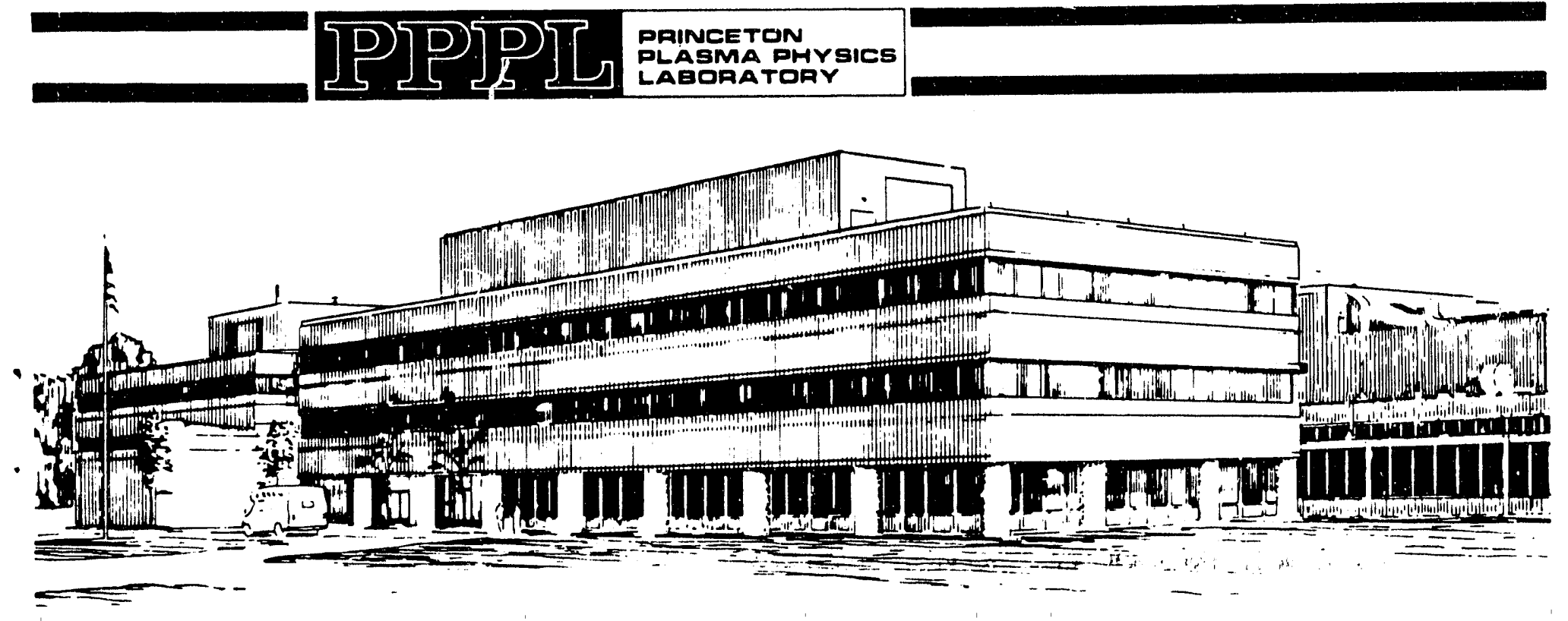


\section{NOTICE}

This report was prepared as an account of work sponsored by an agency of the United States Government. Neither the United States Government nor any agency thereof, nor any of their employees, makes any warranty, express or implied, or assumes any legal liability or responsibility for the accuracy, completeness, or usefulness of any information, apparatus, product, or process disclosed, or represents that its use would not infringe privately owned rights. Reference herein to any specific commercial produce, process, or service by trade name, trademark, manufacturer, or otherwise, does not necessarily constitute or imply its endorsement, recommendation, or favoring by the United States Government or any agency thereof. The views and opinions of authors expressed herein do not necessarily state or reflect those of the United Statess Government or any agency thereof.

\section{NOTICE}

This report has been reproduced from the best available copy.

Available in paper copy and microfiche.

Number of pages in this report: 25

DOE and DOE contractors can obtain copies of this report from:

Office of Scientific and Technical Information

P.O. Box 62

Oak Ridge, TN 37831;

(615) $576-8401$.

This report is publicly available from the:

National Technical Information Service

Department of Commerce

5285 Port Royal Road

Springfield, Virginia 22161

(703) $487-4650$ 


\title{
Modeling of MeV Alpha Particle Energy Transfer to Lower Hybrid Waves
}

\author{
J. Schivell, D. A. Monticello, N. Fisch, and J.-M. Rax* \\ Princeton Plasma Physics Laboratory, \\ Princeton University, P. O. Box 451, Princeton, New Jersey 08543
}

Classification: 5240 (Plasma Interactions)

\begin{abstract}
The interaction between a lower hybrid wave and a fusion alpha particle displaces the alpha particle simultaneously in space and energy. This results in coupled diffusion. Diffusion of alphas down the density gradient could lead to their transferring energy to the wave. This could, in turn, put energy into current drive. An initial analytic study was done by Fisch and Rax. Here we calculate numerical solutions for the alpha energy transfer and study a range of conditions that are favorable for wave amplification from alpha energy. We find that it is possible for fusion alpha particles to transfer a large fraction of their energy to the lower hybrid wave. The numerical calculation shows that the net energy transfer is not sensitive to the value of the diffusion coefficient over a wide range of practical values. An extension of this idea, the use of a lossy boundary to enhance the energy transfer, is investigated. This technique is shown to offer a large potential benefit.
\end{abstract}

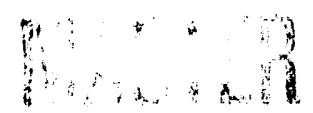




\section{Introduction}

Lower hybrid current drive has been an attractive alternative to inductive current drive, but for reactors there has been concern that fusion alpha particles would be a strong absorber of lower hybrid power[1,2]. Recently, however, it has been pointed out[3] that under the right conditions the alpha population can actually amplify the wave, thereby harnessing some of the energy of the alpha population for the current drive. The necessary conditions require that there be a density gradient of fast alphas, and that $k_{\theta}$ of the wave be in the correct direction. The process utilizes the fact that transfer of energy between wave and particle is accompanied by a change in the particle's gyrocenter. Thus, diffusion in energy is coupled directionally with diffusion in space, and, with the correct choice of direction, a population of alphas diffusing in space under the influence of the wave will, on the average, transfer energy to the wave.

This possibility was discussed in a paper by Fisch and Rax[3], where they estimated the amount of energy transfer in the limiting case of infinite diffusion coefficient. In this paper we describe a finite-difference calculation used to solve the differential equation that models the process for finite diffusion coefficient. We simulate the limiting case (by taking a large value for the diffusion coefficient) to verify the analytic results of Ref. [3]. Small errors in the equations have been corrected. Then the energy transfer is calculated for a range of practical values and is found to be considerable. Finally, we modify the boundary conditions to introduce particle losses that enhance the energy transfer from particles to wave. The effect appears to be very promising. 


\section{The Process}

The process by which the energy and space diffusion are coupled has been described in Ref. [3]. It is summarized here. An example of the interaction is shown in Fig. 1, in which an alpha particle is encountered by a wave traveling in the y-direction. As long as the velocity of the alpha, $v_{\perp}$, in the plane is greater than or equal to the wave phase velocity, $\omega / k_{y}$, the two interact, and the alpha receives an increment of velocity, $\Delta v_{y}$ (positive or negative). As a result, the gyrocenter of the particle is shifted by an amount $\Delta \mathrm{x}_{\mathrm{gc}}$. The momentum change is $m_{\alpha} \Delta v_{y}$, and the energy change is $m_{\alpha} v_{y} \Delta v_{y}$. The gyrocenter shift is equal to $\Delta \mathrm{v}_{\mathrm{y}} / \Omega_{\alpha}$, where $\Omega_{\alpha}=2 \mathrm{eB} / \mathrm{m}_{\alpha}$. Therefore, $\Delta \mathrm{x}_{\mathrm{gc}}=\Delta \mathrm{E}\left(\mathrm{k}_{\mathrm{y}} / \mathrm{m}_{\alpha} \Omega_{\alpha} \omega\right)$, showing the coupling between energy transfer and spatial shift. The guiding-center shift is inversely proportional to the wave phase velocity. We would choose a value like $\omega / \mathrm{k}_{\mathrm{y}} \sim 6 \mathrm{x}$ (ion thermal velocity), in order to avoid wave interaction with the thermal ions. For the case of total alpha energy transfer equal to the production energy, $E_{\alpha 0}=3.5 \mathrm{MeV}=\mathrm{m}_{\alpha} \mathrm{v}_{\alpha 0}{ }^{2 / 2}$, the guiding-center would move by $L=v_{\alpha 0} \mathrm{k}_{\mathrm{y}} / 2 \omega \Omega_{\alpha} \sim 20 \mathrm{~cm}$ in a 5-T field. Note that, for a given density gradient, more energy is extractable by making L long, that is, making the phase velocity low (so long as $\mathrm{L}<\mathrm{a}$, where a is the minor radius, which is generally satisfied anyway).

The differential equation describing the alpha density as a function of energy, position, and time, under the influences of this "quasi-linear" diffusion, slowing down on electrons, and a source is [3]

$$
\frac{\partial \rho}{\partial \tau}=\frac{\partial}{\partial \varepsilon}(\varepsilon \rho)+\left(\frac{\partial}{\partial \varepsilon}+\frac{\partial}{\partial X}\right) \frac{D}{\sqrt{\varepsilon-\varepsilon_{w}}}\left(\frac{\partial}{\partial \varepsilon}+\frac{\partial}{\partial X}\right) \rho+S(\varepsilon, X, \tau)
$$

This equation is in terms of dimensionless quantities:

$$
\begin{aligned}
& \varepsilon=v_{\perp}{ }^{2 / v_{\alpha 0}}{ }^{2} \\
& X=x_{g c} / L
\end{aligned}
$$


$\tau=2 v t$, where $v$ is the slowing-down rate of alphas on electrons

$\varepsilon_{\mathrm{w}}=\left(\omega / \mathrm{k}_{\mathrm{y}} \mathrm{v}_{\alpha 0}\right)^{2}$, the kinetic energy below which the alpha is not in resonance with the wave

$\rho$ is the alpha density

$\mathrm{S}$ is the alpha source

The boundary conditions are determined from following: $D=0$ for $\varepsilon<\varepsilon_{W}$, since there is no wave-alpha resonance there, and the wave exists only in a beam extending laterally from $X=$ 0 to $X=A$--outside that range $D=0$.

\section{Analytic Treatment}

The analysis of the behavior of a population of alphas is, again, summarized from Ref. [3]. The process takes place in a space shown in Fig. 2. It will be convenient to introduce a transformation given by $u=\varepsilon+X$ and $v=\varepsilon-X$. The boundary conditions on the diffusion imply that $\partial \rho / \partial u=0$ on the top and bottom boundaries. Since nothing can take particles across the right boundary, we can take $p=0$ there. Only slowing down (and not diffusion) takes particles across the left, $\varepsilon=\varepsilon_{\mathrm{w}}$, boundary, so one can write the flux at that boundary as $-\varepsilon \rho$; equivalently one takes the boundary condition $\partial \rho / \partial u=0$. The diagram of the region of wave-particle interaction in this paper differs from that in Ref. [3], because here we draw the diagonal along which diffusion occurs at $45^{\circ}$ to the right, a line of constant $\mathrm{v}$. This is consistent with the form of the diffusion operator in Eq. (1). This difference does not affect the conclusions, since it is merely equivalent to a replacement of $\mathrm{X}$ by $(\mathrm{A}-\mathrm{X})$. One should think of $\mathrm{X}=\mathrm{A}$ being closer to the center of the plasma, where the alpha particie density would presumably be higher, so that the overall net energy transfer is from the particles to the wave. This is, of course, always possible by making the proper choice of $k_{\theta}$. 
Consider a short pulse of alphas produced at $\left(\varepsilon_{0}, X_{0}\right)$, i. e., a $\delta$-function source. Consider the case in which $\mathrm{D} \rightarrow \infty$. Initially the population diffuses along the $45^{\circ}$ diagonal specified by $P_{0}=\varepsilon_{0}-X_{0}$, and the density immediately becomes uniform along that line. The energy exchanged, wave to alpha, is given simply by

$$
\mathrm{W}_{0}\left(\mathrm{X}_{0}, \varepsilon_{0}\right)=\frac{1}{2}\left(\varepsilon_{\max }+\varepsilon_{\min }\right)-\varepsilon_{0}
$$

where the first term is the final average kinetic energy. Along the diagonal, $\varepsilon_{\max }=\varepsilon_{0}-X_{0^{+}}$ $\mathrm{A}$, and $\varepsilon_{\min }$ is given by

$$
\varepsilon_{\min }= \begin{cases}\mathrm{P}_{0}, & \text { if } \mathrm{P}_{0} \text { is in region (b) } \\ \varepsilon_{\mathrm{w}}, & \text { if } \mathrm{P}_{0} \text { is in region (a) }\end{cases}
$$

(see Fig. 2). Substituting into Eq. (2), we obtain

$$
\mathrm{W}_{0}\left(\mathrm{X}_{0}, \varepsilon_{0}\right)= \begin{cases}\mathrm{A} / 2-\mathrm{X}_{0}, & \text { if } \mathrm{P}_{0} \text { is in region (b) } \\ \left(\mathrm{A}-\mathrm{X}_{0}\right) / 2-\left(\varepsilon_{0}-\varepsilon_{\mathrm{w}}\right) / 2, & \text { if } \mathrm{P}_{0} \text { is in region (a) }\end{cases}
$$

This instantaneous energy exchange can be positive or negative; for $\mathrm{X}_{0}$ near $\mathrm{A}$, it is negative.

The subsequent slowing down and diffusion are considered as a repeating alternation of slowing down for a short $\Delta t$, followed by diffusion for an equal $\Delta t$. Each slowing down takes the alpha population from a diagonal $\mathrm{P}$ to a left-shifted line tilted slightly toward the vertical. The diffusion then spreads the density uniformly along a band around the average $45^{\circ}$ diagonal. As shown in Ref. [3], in region (b) the energy exchange vanishes.

In region (a) the energy exchange is no longer zero. The starting value of $\mathrm{P}$ depends on whether the alphas were produced in region (b) or (a). In the former case, the starting value is $\mathrm{P}_{0 \mathrm{a}}=\varepsilon_{\mathrm{w}}$; in the latter, $\mathrm{P}_{0 \mathrm{a}}=\mathrm{P}_{0}=\varepsilon_{0}-\mathrm{X}_{0}$. Modifying the derivation in Ref. [3] for 
$\mathrm{X} \rightarrow \mathrm{A}-\mathrm{X}$ and correcting minor errors ${ }^{\dagger}$ we have for the exchange subsequent to the initial exchange

$$
\mathrm{W}_{\mathrm{L}}\left(\mathrm{P}_{0 \mathrm{a}}, \tau\right)=\frac{\varepsilon_{\mathrm{w}}}{(1-\mathrm{s})}\left\{-\tau-\frac{1}{\mathrm{~s}}\left(\mathrm{e}^{-\tau / 2}-1\right)+\mathrm{s}\left(\mathrm{e}^{\tau / 2}-1\right)\right\}
$$

where $s \equiv 2 \varepsilon_{\mathrm{w}} /\left(\mathrm{P}_{0 \mathrm{a}}+\mathrm{A}+\varepsilon_{\mathrm{w}}\right)$. All the particles are gone by the time $\tau=\tau_{\max }$, where $\tau_{\max }=2 \ln (1 / \mathrm{s})$; see Ref. [3]. Therefore, if the rf power is on continuously, the ultimate value of $W_{L}$ is

$$
\mathrm{W}_{\mathrm{L}}\left(\mathrm{P}_{0 \mathrm{a}}, \tau_{\max }\right)=\frac{\varepsilon_{\mathrm{w}}}{(1-\mathrm{s})}\{2 \ln (\mathrm{s})+1 / \mathrm{s}-\mathrm{s}\}
$$

The total energy exchanged from wave to alpha is $\mathrm{W}=\mathrm{W}_{0}+\mathrm{W}_{\mathrm{L}}$. In deriving Eqs. (5) and (6), certain approximations were made, in addition to taking the limit $\mathrm{D} \rightarrow \infty$. There is no limit in which these approximations are rigorous, but, what we show [through numerical solution of Eq. (1)] in the following sections is that these analytic expressions for $W_{L}$ are very nearly correct for $\mathrm{D} \rightarrow \infty$.

Note that $\mathrm{W}_{\mathrm{L}}$ is always positive. If $\mathrm{X}_{0}$ is chosen so that $\mathrm{W}_{0}$ is negative, meaning that the alphas give energy to the wave, then when they are in region (a), the wave "gives back" energy to the alphas. For this reason, a scenario with only short pulses of rf appears advantageous.

\section{Maximum Energy Transfer}

The quantity $\varepsilon_{()}$, the initial perpendicular energy, is given by the alpha production: the pitch angle determines an $\varepsilon_{0} \leq 1.0$. The distribution in $\varepsilon_{0}$ is uniform. To maximize the 
number of alphas diffusing to lower energy, we need $\mathrm{X}_{0}$ to be near the top of the region. In the practical situation $\mathrm{k}_{\theta}$ would be chosen so that $\mathrm{X}_{0}$ is toward the center of the plasma with $\mathrm{X}=0$ toward the periphery. The quantity $\varepsilon_{\mathrm{w}}$ is the lowest perpendicular kinetic energy, relative to the total kinetic energy at production, of an alpha that is resonant with the wave. For putting the alpha energy into electrons, choose $\varepsilon_{w}$ well above ion thermal energies, for example $\omega / \mathrm{k}_{\theta} \sim 6 \mathrm{v}_{\mathrm{T}}$, to avoid ion damping. This corresponds to $\sim 500 \mathrm{keV}$ and $\varepsilon_{\mathrm{w}}=0.15$.

Using the analytic expression (6), we did a scan of the three parameters, $\varepsilon_{0}$, $\varepsilon_{w}$, and $A$, to locate the regions with the most energy exchange from alphas to wave. The energy exchange "saturates" at around $A=1$. Figure 3 shows the variation with $\varepsilon_{0}$ and $\varepsilon_{w}$ for $A=1$ and $\mathrm{X}_{0}=0.95$. The initial energy exchanged is plotted, as well as the net taking into account the "give back" during the alpha slowing down. Note that for a normal population of alphas, isotropic in velocity space, one would need to integrate over $\varepsilon_{0}$ to get the total energy transfer.

For the short-pulse of scenario, clearly, the lower the value of $\varepsilon_{w}$, the more energy from alpha to wave; however, with continuous if there is a broad maximum in the neighborhood of $\varepsilon_{\mathrm{w}} \sim 0.2$. This is an additional reason for choosing $\varepsilon_{\mathrm{w}}$ in the vicinity of (but above) 0.15 mentioned above.

\section{Comparison to Numerical Solution}

The analytic study described above has been supplemented by a finite-difference solution of Eq. (1). This calculation allows us to model the effects of finite values of the diffusion coefficient, D, and altered boundary conditions intended to enhance energy exchange. This finite-difference solution can be used in the future to model other scenarios, such as applying the wave power in short pulses, also for the purpose of enhancing the fraction of the particle energy delivered to the wave.

We begin with the transformation $u=\varepsilon+X$ and $v=\varepsilon-X$. While it does no good to transform the whole equation, it does simplify writing the diffusion term, since it implies 
$\partial / \partial \varepsilon+\partial / \partial \mathrm{X}=2 \partial / \partial u$. Figure 4 shows the grid that is used, along with the locations of diagonals and the points used in the central differences. For the diffusion term we choose the finite difference form to be space centered and use the Crank-Nicholson method [4]; for the slowing-down term we take the upwind difference. The difference equation is then

$$
\begin{gathered}
\rho_{j, k}^{i+1}=\rho_{j, k}^{i}+\frac{\grave{\Delta} \tau}{\Delta \varepsilon}\left[\varepsilon_{j+1} \rho_{j+1, k}^{i}-\varepsilon_{j} \rho_{j, k}^{i}\right] \\
+\left(1-f_{i m p}\right) \frac{4 \Delta \tau}{(\Delta u)^{2}}\left[\kappa_{j+1 / 2}\left(\rho_{j+1, k+1}^{i}-\rho_{j, k}^{i}\right)-\kappa_{j-1 / 2}\left(\rho_{j, k}^{i}-\rho_{j-1, k-1}^{i}\right)\right] \\
+f_{i m p} \frac{4 \Delta \tau}{(\Delta u)^{2}}\left[\kappa_{j+1 / 2}\left(\rho_{j+1, k+1}^{i+1}-\rho_{j, k}^{i+1}\right)-\kappa_{j-1 / 2}\left(\rho_{j, k}^{i+1}-\rho_{j-1, k-1}^{i+1}\right)\right] \\
+\Delta \tau S_{j, k}^{i}
\end{gathered}
$$

where $\kappa_{j}=D / \sqrt{\varepsilon_{j}-\varepsilon_{w}}$, and $f_{i m p}$ is normally set $=0.5$. To make the method second-order in time, we take a half step, with $f_{i m p}=1.0$, to get half-step values for the slowing-down term. The boundary conditions are $\rho=0$ on the right (diagonal) and $\partial \rho / \partial u=0$ on the left, top, and bottom. First-order differences are used in implementing the boundary conditions. The sets of simultaneous equations generated by the implicit differences are solved by the method of Richtmyer and Morton [5]. We step through the diagonals, one by one; on each there is a system of equations for the $\rho^{i+1}$; Ref. [5] gives a simple recursion method for solving the system subject to the boundary conditions.

The method and the computer program that implements it were tested by using a test function for the density, $\rho$. The function was chosen to satisfy the boundary conditions on all four boundaries. The function, $\rho$, was substituted into Eq. (1) to determine the corresponding source function, $S(\varepsilon, X, \tau)$. That source was used in the finite-difference program to calculate $\rho(\varepsilon, X, \tau)$ nurnerically. The results were compared with the assumed $\rho$ to verify the method and to test the rate of convergence. The function chosen is the product of four polynomials. Substitution into the PDE leads to a large amount of manipulation, which, fortunately, is easily performed with the Macsyma symbolic manipulation system [6]. The Fortran code for the source function was also produced by Macsyma. 
Figure 5 shows the results of the testing, monitored at two representative points. For the testing we used $\mathrm{D}=0.3, \varepsilon_{\mathrm{w}}=+0.1$, and $\mathrm{A}=0.5$. The test function looks like a smooth hill, with the edges $=0$ at the boundaries, and the peak at the center of the space. The function was multiplied by an exponentially decaying factor, with time constant $\tau_{\text {decay }}=$ 0.0844 . The errors plotted are at time $\tau=0.15$. The errors displayed are at points near the left-hand boundary, where the error is largest. The error varies more slowly than the first power of step size, apparently because of the factor $\sqrt{\varepsilon_{j}-\varepsilon_{w}}$ in the denominator. Nevertheless, the error is clearly converging on zero with decreasing step size, indicating the correctness of the method.

The goal of the calculation is to obtain the energy exchanged between fast alpha particles and the wave. To calculate this, once we have the alpha density, $\rho(\varepsilon, X, \tau)$, we multiply the PDE through by $\varepsilon$ and integrate over all $\varepsilon$ and $X$ :

$$
\frac{\partial}{\partial \tau} \int \varepsilon \rho d \varepsilon d X=\int \varepsilon \frac{\partial}{\partial \varepsilon}(\varepsilon \rho) d \varepsilon d X+4 \int \varepsilon \frac{\partial}{\partial u} \kappa \frac{\partial \rho}{\partial u} d \varepsilon d X+\int \varepsilon S d \varepsilon d X .
$$

This represents

$$
\begin{aligned}
& \frac{\partial}{\partial \tau} \int\left(\alpha \text { stored energy) } \mathrm{d} \varepsilon \mathrm{dX}=\int(\text { power from electron drag) } \mathrm{d} \varepsilon \mathrm{dX}\right. \\
& \left.\quad+\int \text { (power from the wave }\right) \mathrm{d} \varepsilon \mathrm{dX}+\int(\alpha \text { source power }) \mathrm{d} \varepsilon \mathrm{dX}
\end{aligned}
$$

where positive quantities represent power flowing to the alpha particles. The second term on the right is the power we are interested in. Under some conditions, in particular when the majority of alpha diffusion in space is accompanied by a lowering of alpha kinetic energy, the second term is negative, implying a net transfer of energy from alphas to the wave.

For comparison between the analytic and the finite-difference calculations, we select two cases. Case $\mathrm{I}$ has $\mathrm{A}=1 ., \varepsilon_{\mathrm{w}}=0.15, \varepsilon_{0}=1.0, \mathrm{X}_{0}=0.95$, which locates the source in region (a), and Case II is in region (b), with $A=0.5, \varepsilon_{w}=0.10, \varepsilon_{0}=1.0, X_{0}=0.4$. The latter case will demonstrate all the features of the predicted time evolution of the energy 
exchange, namely, a rapid initial exchange, followed by no exchange for the rest of the time in region (b), followed by a gradual return of a portion of the energy while in region (a).

To illustrate the behavior of the energy exchange as a function of time, we first plot, in Fig. 6, alpha-to-wave energy exchange for Case Il mentioned above (source in region (b)). As above in the analytic calculation, the source was taken to be a $\delta$-function in $\varepsilon, X$, and $t$. (Thus, the result here can be considered to be a Green's function for the energy exchange.) In this plot we have inverted the sign of the energy exchange so that alpha-towave is plotted as a positive quantity. Figure 6 is the result from the finite-difference calculation, integrated as described above. As expected from the analytic analysis, the energy exchange begins with an immediate transfer to the wave, after which the exchange during the rest of the time in region (b) is zero. When the alphas are in region (a), the wave "pays back" some of the energy, but, by the time all of the alphas have slowed down below $\varepsilon_{\mathrm{w}}$ (in this case $\tau / \tau_{\mathrm{s}}=3$.), there is still a net amount of energy that has been transferred to the wave. For this case the analytic analysis gives $\mathrm{W}_{0}=15 \%$ |using $E q$. (4)| for the initial transfer from alpha particles to wave. Using Eq. (5) for the return of energy from wave to alpha particles gives the curve in Fig. 6 labeled "Eq. 5". The agreement is very good, verifying the analytic formula.

The convergence of the energies as a function of step size is very satisfactory. As the $\varepsilon$ (and $X$ ) step was varied from 0.03 and 0.003 , the energy unaccounted for at the end of the calculations went down from $12 \%$ to $1.3 \%$ and extrapolates to a value extremely close to zero for step size equal to zero. Also, the energy exchanged from alphas to wave extrapolates, as a function of step size, to the same value as the analytic calculation within $\sim 0.1 \%$; the difference for the step size used for the results below $(0.003)$ is $0.25 \%$.

\section{Optimal Energy-Transfer Case}


We now examine in detail Case I, namely, $A=1$., $\varepsilon_{\mathrm{w}}=0.15, \varepsilon_{0}=1.0, \mathrm{X}_{0}=0.95$. Although a slightly higher energy transfer to the wave could be obtained with $\varepsilon_{\mathrm{W}} \sim 0.3$, as may be seen in Fig. 3, the value chosen is more nearly suited to the average value of $\varepsilon_{0}$ and is more practical, since it would employ the lowest frequency wave source consistent with the $6 v_{T_{i}}$ requirement. In this case the source is in region (a), so there is no period of zero exchanged power. Results from the analytic formulas are as follows:

$$
\begin{array}{lll}
\mathrm{W}_{0}= & 40.0 \% & \text { (initial transfer) } \\
\mathrm{W}_{\mathrm{L}}= & -19.5 \% & \text { (later transfer) } \\
\mathrm{W}= & 20.5 \% & \text { (net transfer) }
\end{array}
$$

The analytic formulas are for $\mathrm{D} \rightarrow \infty$; the finite-difference calculation shows that the process saturates for $D=10$ and above, where the analytic approximation, again, is numerically verified.

Figure 7 shows the energy transferred as a function of time for this case. When $D=10$, as we have taken above, the behavior is as expected for a source in region (a), that is, after the initial, immediate transfer, the "give back" begins immediately. Interestingly, we find that, as the strength of $D$ is reduced, its value has much more effect on the early energy exchange than on the net amount. Likely values of $D$ would probably be in the range $3>D$ $>0.3$ [7], over which the net energy exchange varies only slightly. This has the fortunate implication that the strength of the wave can vary over a wide range while still effecting nearly optimal energy exchange.

\section{Enhancing the Energy Transfer to the Wave}

Particles near the boundary $\varepsilon=\varepsilon_{\mathrm{W}}$ can only take energy from the wave as they diffuse up along the diagonal; therefore, it would be advantageous to get rid of them. It would be possible to introduce perturbations into the plasma to cause particles to cross that boundary in excess of the collisional slowing down. To model the effect of such a particle loss, we have investigated changing the boundary condition on the left boundary, $\varepsilon=\varepsilon_{w}$, from $\partial \rho / \partial u=0$ 
to $\partial \rho / \partial u+\lambda u=0$, where $\lambda$ is an adjustable "leakage" parameter. The result is that a relatively small value of $\lambda$ produces a large beneficial effect. This is shown in Fig. 8, where, as before, the energy exchanged as a function of time for a $\delta$-function source is plotted. $D=$ 0.3. The coefficient $\lambda$ is in effect the fractional variation of the particle density per unit distance in $u$ at the boundary. Starting from the net energy exchange of $19 \%$ for the case of no leakage, we find that $\lambda=0.3 \%$ increases the energy exchange to $26 \%$, while $\lambda=3 \%$ takes it up to $51 \%$. The strong value of $\lambda=50 \%$ yièlds $74 \%$ exchange. The possibility of enhancing the energy transfer to the wave, if such a means can be found, appears very promising.

\section{Further Applications of the Program}

Certainly, other scenarios can be modeled. One example would be using short pulses of rf, rather than continuous power, to derive the maximum benefit from the initial energy exchange (this would be an alternative to the lossy boundary). Another example would be allowing a general variation of $\mathrm{D}$ as a function of $\mathrm{X}$, representing a more realistic localization of the wave in space.

\section{Discussion}

To look at the actual magnitude of the diffusion constant, D, and the power available from the alphas, consider ITER. It needs on the order of $90 \mathrm{MW}$ for Lower Hybrid Current Drive. This would give $D \sim 0.3$ to $D \sim 3 .[2,7]$. As shown above, this is in a range that produces practical energy exchange from the alpha population to the wave. The amount would be approximately the fusion power of $1000 \mathrm{MW}$, times a fraction of $20 \%$ that goes to the alphas, times a fraction of $40 \%$ that is transferred from the alphas to the wave. The result is $80 \mathrm{MW}$ from alphas to wave, or just about the amount needed to keep the current drive going. 
If the rate of normal collisional diffusion were to exceed the quasi-linear diffusion considered in this paper, then the effect of the latter would be diluted. To make the comparison we can convert the dimensionless D used here to SI units. Recalling that our time is in units of $(2 v)^{-1}$, and that length is in units of $L$, we have that the SI value is $D_{S I}=$ $2 v \mathrm{~L}^{2} \mathrm{D}$. For the mean value $\mathrm{D}=1$, with $v^{-1}=0.4 \mathrm{~s}$, and $\mathrm{L}=20 \mathrm{~cm}, \mathrm{D}_{\mathrm{SI}}=(0.2 \mathrm{~m})^{2} \times 1 . /$ $0.2 \mathrm{~s}=0.2 \mathrm{~m}^{2} / \mathrm{s}$. One of the smallest values of $\mathrm{D}$ we have considered is $\mathrm{D} \sim 0.1$, or $\mathrm{D}_{\mathrm{SI}} \sim$ $0.02 \mathrm{~m}^{2} / \mathrm{s}$. This is of the same order of magnitude as possible fast-alpha coilisional diffusion [8]. In that case one would expect the energy exchange from alpha to wave to be diluted by the collisional diffusion. That puts a lower bound on the necessary wave intensity for an effective energy exchange.

\section{Summary}

We have provided numerical justification to the treatment of Ref. [3] for the $D \rightarrow \infty$ limit, we have shown numerically how that limit is approached for finite $D$, and we have numerically investigated the useful effect of leakage of particles out of the resonant region in optimizing the transfer of alpha-particle energy to waves.

\section{Acknowledgments}

This work was supported by U. S. Department of Energy contract No. DE-AC02-76CHO3073. We would like to thank the following people for helpful conversations: D. Ignat, H. K. Park, G. Taylor, J. Stevens, W. W. Lee, and K. L. Wong. 


\section{Notes}

*Permanent address: Commissariat a L'Energie Atomique, Centre D'Etudes de Saclay, 91191 Gif sur Yvette, Cedex, France.

$\dagger$ In Eq. (14) of Ref. [3], the sign in the denominator should be reversed, so that it would read

$$
\frac{\mathrm{dN}}{\mathrm{d} \tau}=-\frac{\varepsilon_{\mathrm{w}}}{\mathrm{P}(\tau)-\varepsilon_{\mathrm{w}}} \mathrm{N}(\tau)
$$

Nevertheless, Eq. (15) is correct. In Eq. (16) we have corrected the constant factors in front of the first and third terms in the brackets. As a result, each term has a factor of 4. A factor of $1 / 4$ in front cancels these factors, giving finally Eq. (5) in this paper.

\section{References}

1. K.-L. Wong and M. Ono, Nucl. Fusion 24, 615 (1984)

2. E. Barbato, F. Santini, Nucl. Fusion 31, 673 (1991)

3. N. J. Fisch and J.-M. Rax, Phys. Rev. Lett. 69, 612 (1992)

4. David Potter, Computational Physics (Wiley, New York, 1973)

5. Robert D. Richtmyer and K. W. Morton, Difference Methods for Initial-Value Problems (Interscience div. of Wiley, New York, 1967)

6. Computer-Aided Mathematics Group, Symbolics, Inc., Cambridge, MA 02142, USA.

7. N. J. Fisch and J.-M. Rax, Nucl. Fusion 32, 549 (1992)

8. S. J. Zweben, et al., Nucl. Fusion 31, 2219 (1991) 


\section{Figure captions}

1. Schematic diagram of the coupling between the absorption of energy from the wave by an alpha particle and the shift of its gyrocenter.

2. The effects of diffusion and slowing down on alpha particle energy and location. The coordinates are dimensionless [see text]. The source is at $\left(\varepsilon_{0}, \mathrm{X}_{0}\right)$.

3. Energy exchange from alpha particles to wave as a function of the minimum resonance kinetic energy.

4. (a) Grid for the finite-difference calculation of alpha particle energy and location. On the top, bottom, and left boundaries $\partial \rho / \partial u=0$, except in the case with leakage [see text]. Note 1: iteration continues through the upper left corner. (b) Points used in differencing.

5. Difference between finite-difference solution and test function vs. spatial (and energy) step size. Test function has amplitude of 3.

6. Time-integrated energy transfer from alpha particles to wave for Case II--source in region (b).

7. Time-integrated energy transfer from alpha particles to wave for Case I--source in region (a)--for a range of values of $\mathrm{D}$, the diffusion coefficient.

8. Time-integrated energy transfer from alpha particles to wave for Case I--source in region (a)--for a range of values of the leakage coefficient, $\lambda . D=0.3$. 

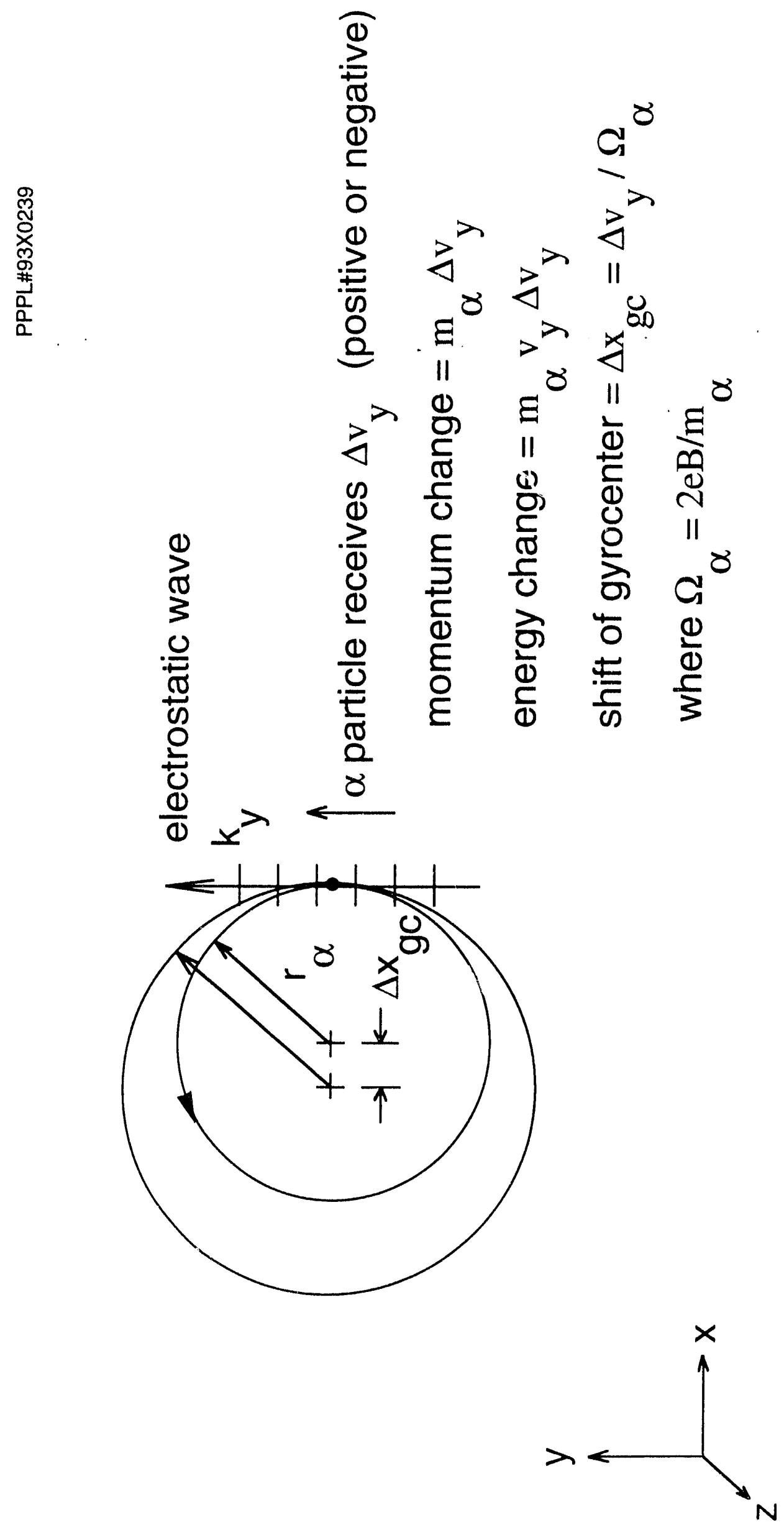


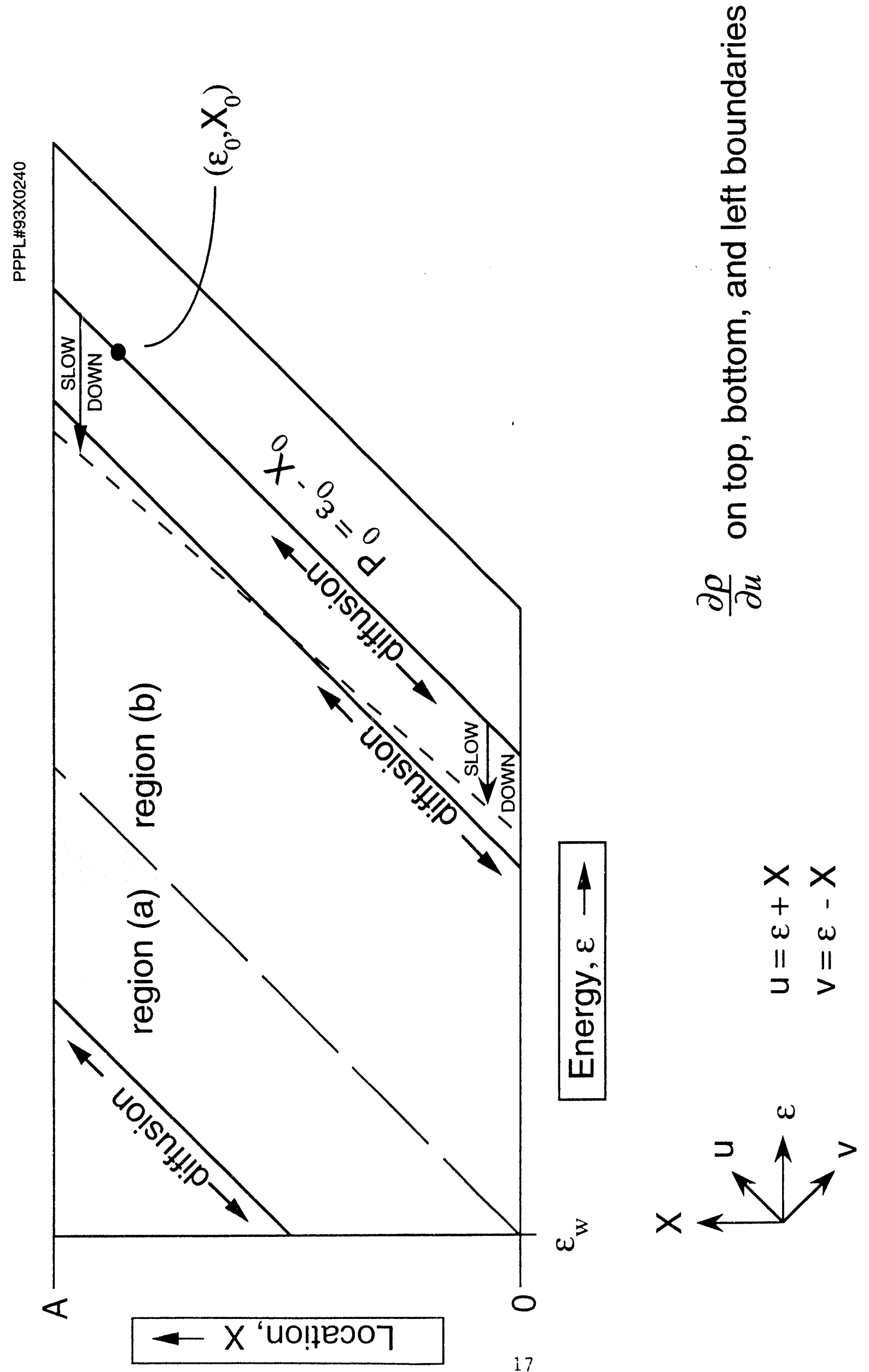




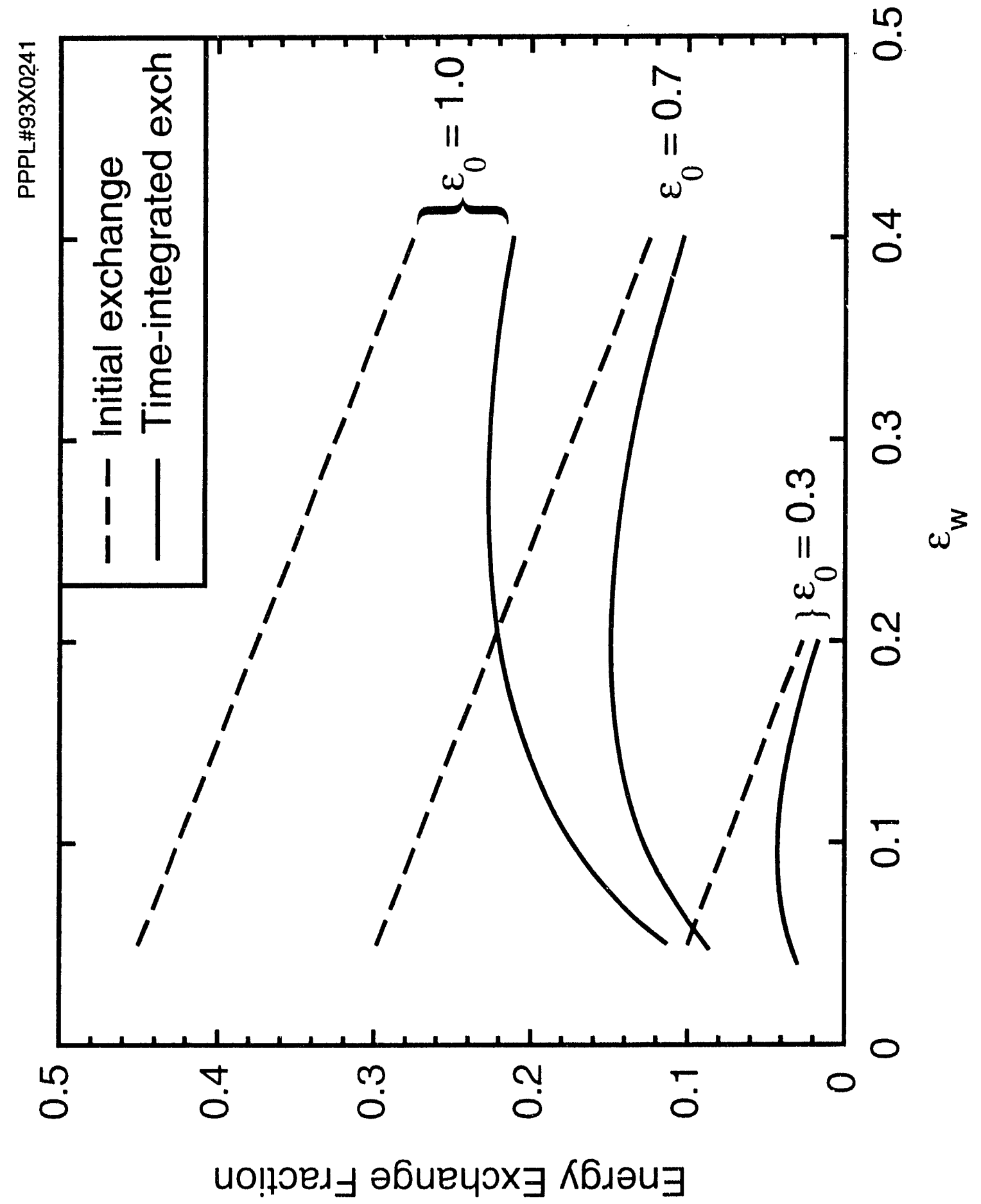




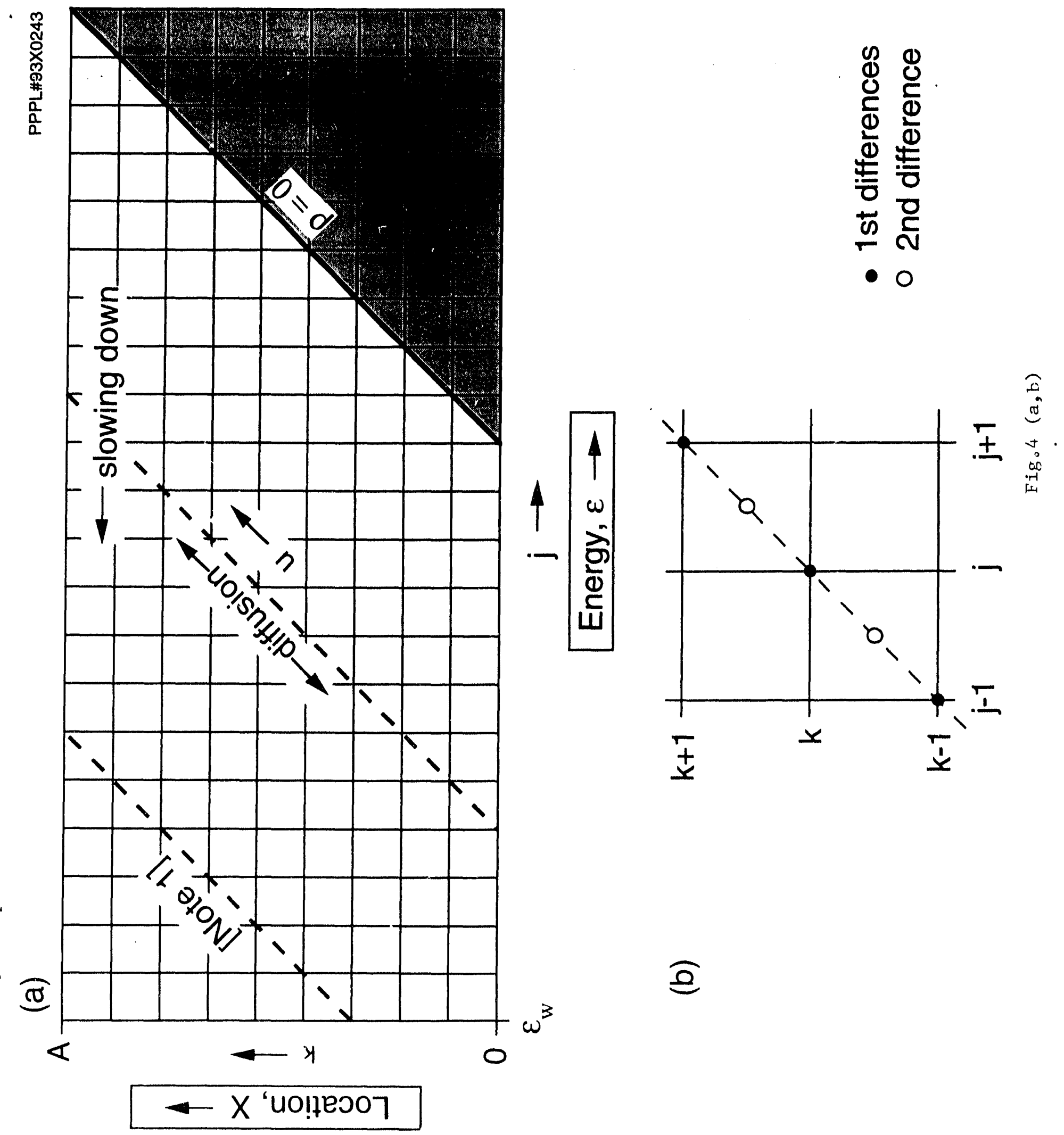




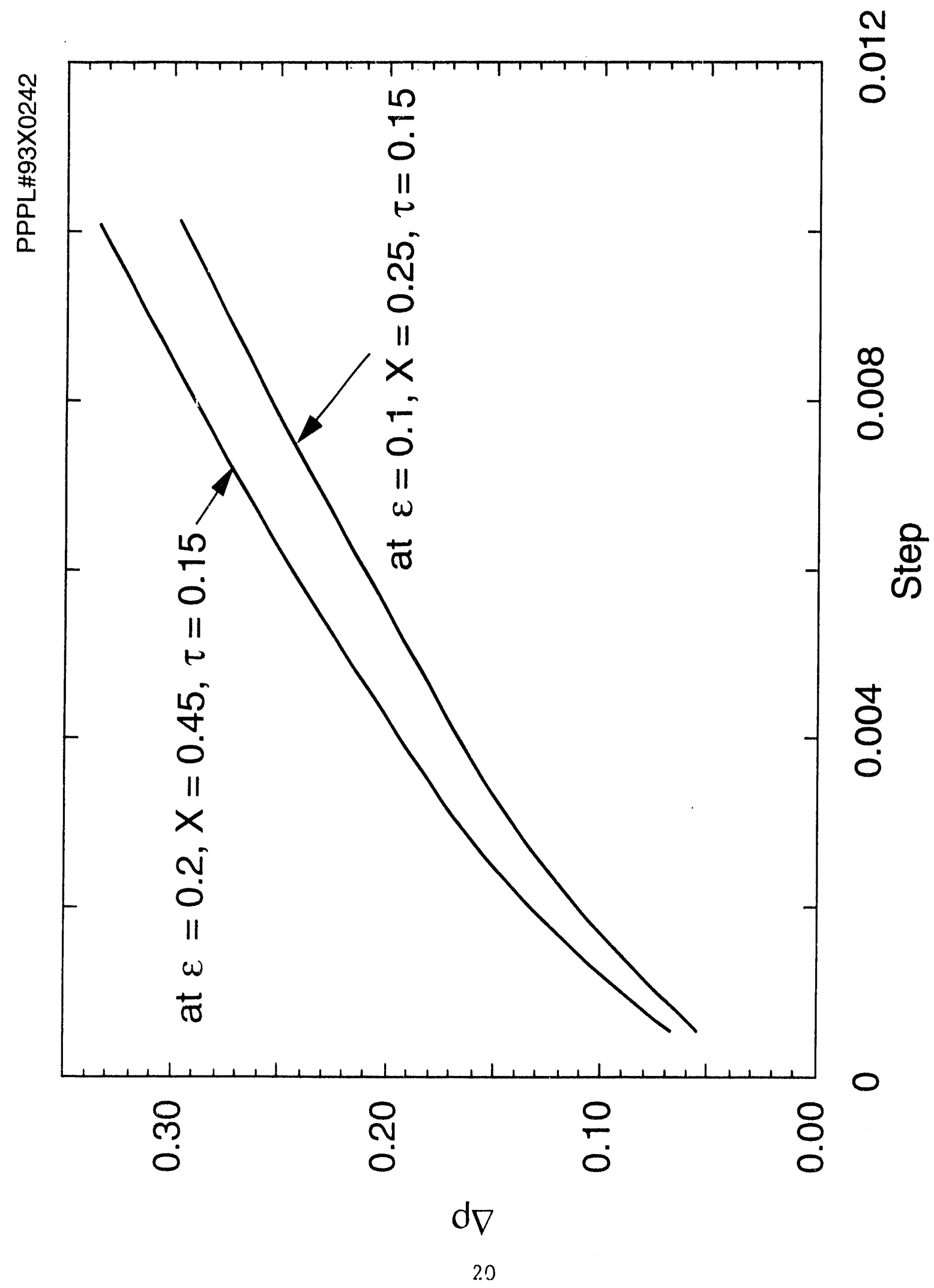




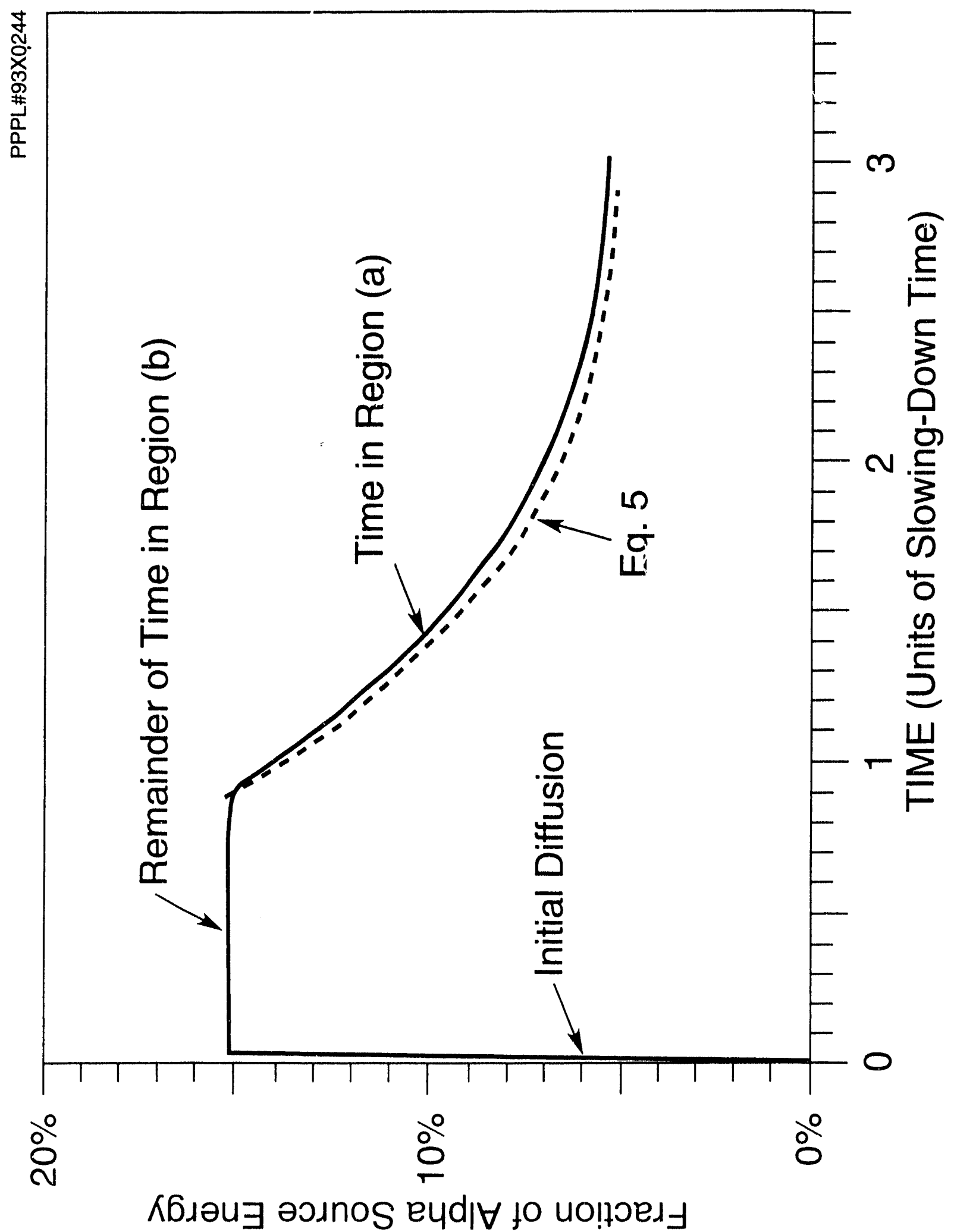

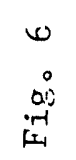




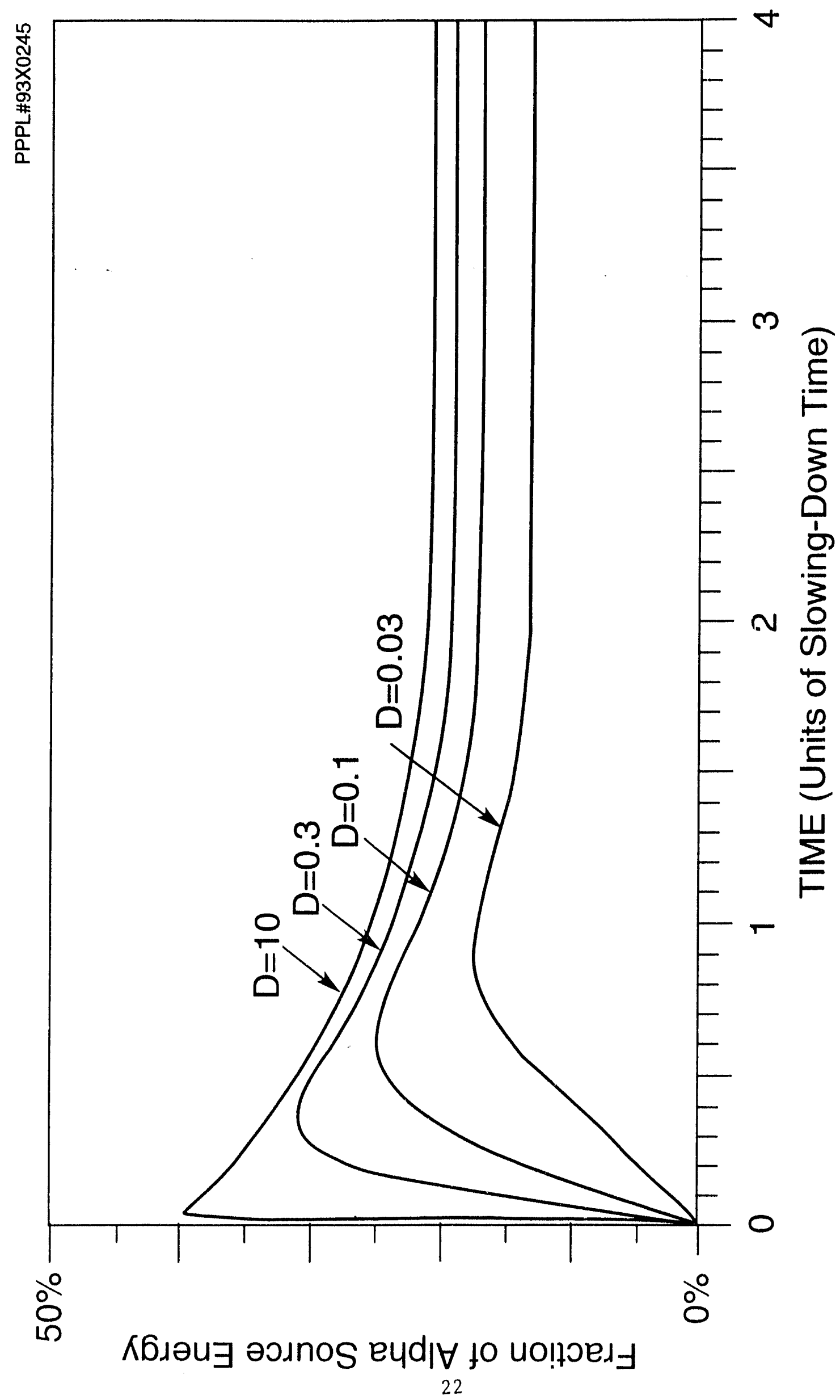




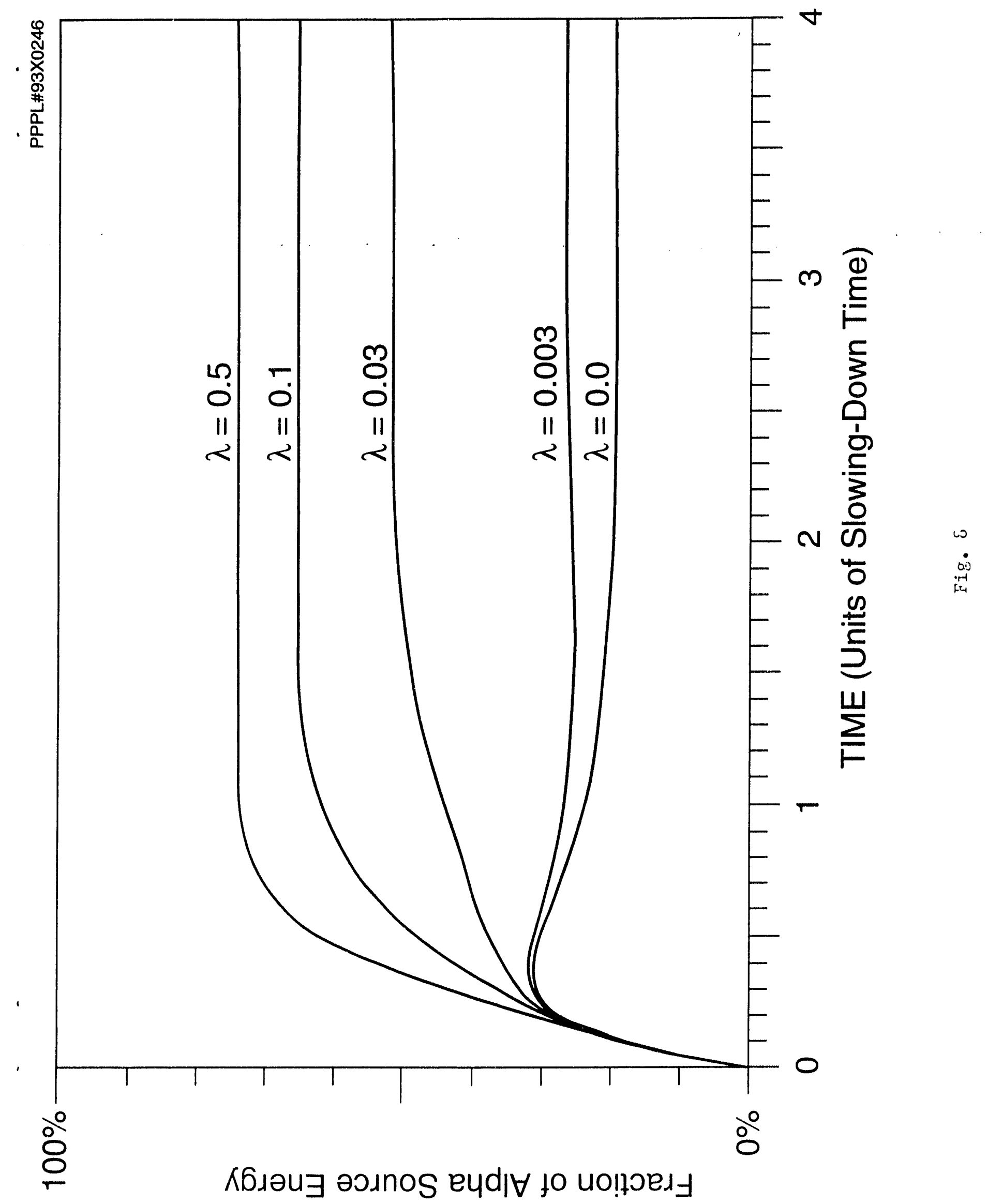


Dr. F. Peoloni, Univ. of Wollongong. AUSTRULIA

Prot. M.H. Brennan, Univ. of Sydney, AUSTRALIA

Plasma Research Lob., Austrelien Nat. Univ., AUSTRALIA

Prof. I.R. Jones, Flinders Univ, AUSTRALIA

Prof. F. Cap, Inst. for Theoretical Physics, AUSTRIA

Prof. M. Heindler, Institut for Theorebische Physik, AUSTRIA

Prof. M. Gooscens, Astronomisch InstituUt, BELGIUM

Ecole Royde Militivire, Lab. de P.hy. Plasmas, BELGIUM

Commission-Europeen, DG. XII-Fusion Prog., BELGIUM

Prol. R. Bouciqub, Rijksunivercitont Gent, BELGIUM

Dr. P.H. Sakanaka, Instituto Fiaica, BRUZIL

Instituto Neciond Do Poequisas Espadrie. INPE, BRUZIL

Documents Ofico, Abomic Energy of Cenada Lid., CANADA

Dr. M.r. Bectyneki, MPB Tectnologies, Inc., CANADA

Dr. H.M. Skaregard, Univ. of Sackatchewen, CANADA

Prof. J. Toichmann, Univ. of Montreal, CANADA

Prot. S.R. Sreenivasen, Univ. of Celgary, CANADA

Prof. T.W. Johnston, INRS-Energio, CANADA

Dr. R. Botion, Contro canadien de fusion megnétique, CANADA

Dr. C.R. James, Univ. of Nberta, CANADA

Dr. P. Lukbc, Komensketho Universzita, CZECHOSLOVAKIA

The Librarian, Cuham Leboratory, ENGLAND

Librey, R61, Ruthertord Appleton Laboratory, ENGLAND

Mrs. S.A. Hulchinsoon, JET Library, ENGLAND

Dr. S.C. Sheme, Univ. of South Pacific, FIJI ISLANDS

P. Mahonen, Univ. of Helsinki, FINLAND

Prof. M.N. Buseac, Ecole Polytectnique, FRANCE

C. Mouther, Lab. de Physique des Milioux lonisess, FRANCE

J. Radet, CENCADARACHE - Bat 506, FRANCE

Prot. E. Economou, Univ. of Crete, GREECE

Ms. C. Rinni, Univ. of loannina, GREECE

Dr. T. Mud, Acadomy Bibliographic Sor., HONG KONG

Preprint Library. Hungarian Acadomy of Sci., HUNGARY

Dr. B. DasGupta, Saha inst. of Nucter Physics, INDIA

Dr. P. Kaw, Inst. for Plasma Research, INDIA

Dr. P. Rosenew, lereed inst of Tectinology, ISPAEL

Libravian, Intormational Contar for Theo Physics, ITALY

Miss C. Do Palo, Associaziono EURATOM-ENEA, ITALY

Dr. G. Groses, Istituto di Fisica del Plasma, ITALY

Prof. G. Rostangni, Istituio Gas lonizzati Dol Cnr, ITALY

Dr. H. Yamato, Tochiba Res Dovel Conter, JAPAN
Prot. I. Kawakami, Hiroshima Univ., JAPAN

Prof. K. Nishikawa, Hiroshima Univ., IAPAN

Director, Jepen Atomic Energy Research Inst., JAPAN

Prof. S. Itoh, Kyushu Univ., JAPAN

Research Info. Ctr., National Instit. for Fusion Science, JAPAN

Prol. S. Tenaka, Kyoto Univ., JAPAN

Librery, Kyoto Univ., JAPAN

Prot. N. Inowe, Univ. of Tokyo, LAPAN

Socrotary, Plasma Section, Electrotechnical Lab., JAPAN

S. Mori, Technicel Advieur, LAERI, LAPAN

Dr. O. Miterai, Kumamoso Inst. of Technology. JAPAN

J. Hyeon-Sook, Korea Atomic Energy Rescarch Inst, KOAEA

D.I. Choi, The Korea Adv. Inst of Sai. Tech., KOREA

Prot. B.S. Liby, Univ. of Waikato, NEW ZEALAND

Inst of Physica, Chinose Acad Sci PEOPLE'S REP. OF CHINA

Librery, Inst of Plasma Physics, PEOPLE'S REP. OF CHINA

Tringhua Univ. Libray. PEOPLE'S REPUBLIC OF CHINA

Z. Li, S.W. Int Phyeics, PEOPLE'S REPUBUC OF CHINA

Prof. J.A.C. Cebred, Instiuto Superior Tecnico, PORTUGAL

Dr. O. Potrus, al I Cuza Univ., Romania

Dr. J. de Villiers, Fusion Studies, AEC, S. AFRICA

Prot. M.A. Hellberg, Univ. of Natal, S. AFRICA

Prot. D.E. Kim. Pohang Inst, of Sci. \& Tech., SO. KOREA

Prof. C.I.E.M.A.T, Fusion Division Library, SPAIN

Dr. L. Sionfib, Univ. of UMEA, SWEDEN

Library, Royed inst. of Tectmology, SWEDEN

Prot. H. Wihotmeon, Chalmers Univ. of Tech., SWEDEN

Contro Phys. Des Plasmas, Ecole Polytech, SWITZERLAND

Bibliotheek, Inst. Voor Plasma-Fysica, THE NETHERLANDS

Asst Prot. Dr. S. Cakir, Middlo East Tech. Univ., TURKEY

Dr. V.A. Gulhikh,Sci. Res. Inst. Electrophys.I Apparatus, USSR

Dr. D.D. Ayubv, Siborian Branch of Academy of Sai., USSA

Dr. G.A. Elieeev, I.V. Kurchatov Inst, USSA

Librerien, The Ukr.SSR Academy of Scionces, USSR

Dr. L.M. Kovrizhnykh, Inst. of Generel Physies, USSR

Kemforectungsanlege GmbH, Zentrabibliothek, W. GERMANY

Bibliothok, Inst. For Plasmalorechung, W. GERMANY

Prof. K. Schindier, Ruhr-Universitt Bochum, W. GERMANY

Dr. F. Wagner, (ASDEX), Max-Planck-Institut, W. GERMANY

Librerien, Max-Plenck-Instiut, W. GERMANY

Prol. R.K. Janew, Inst of Phycios, YUGOSLAVIA 

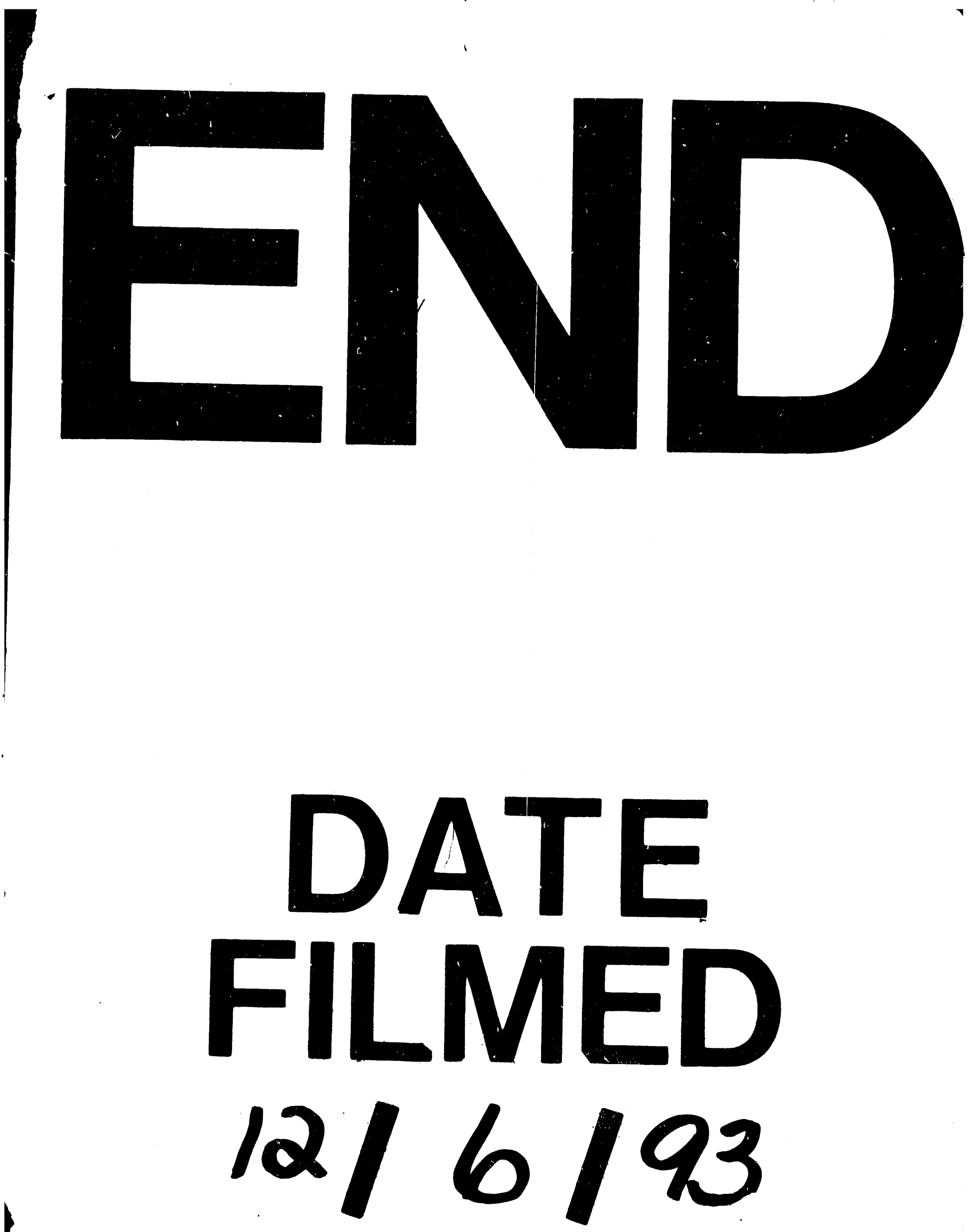
$\mid$

.

. 